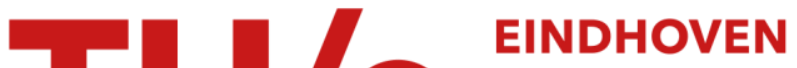 \\ UNIVERSITY OF \\ TECHNOLOGY
}

\section{On the use of hand-held magnifiers during reading}

Citation for published version (APA):

Neve, J. J. (1989). On the use of hand-held magnifiers during reading. Optometry and Vision Science, 66(7), 440-449.

Document status and date:

Published: 01/01/1989

\section{Document Version:}

Publisher's PDF, also known as Version of Record (includes final page, issue and volume numbers)

\section{Please check the document version of this publication:}

- A submitted manuscript is the version of the article upon submission and before peer-review. There can be important differences between the submitted version and the official published version of record. People interested in the research are advised to contact the author for the final version of the publication, or visit the $\mathrm{DOI}$ to the publisher's website.

- The final author version and the galley proof are versions of the publication after peer review.

- The final published version features the final layout of the paper including the volume, issue and page numbers.

Link to publication

\section{General rights}

Copyright and moral rights for the publications made accessible in the public portal are retained by the authors and/or other copyright owners and it is a condition of accessing publications that users recognise and abide by the legal requirements associated with these rights.

- Users may download and print one copy of any publication from the public portal for the purpose of private study or research.

- You may not further distribute the material or use it for any profit-making activity or commercial gain

- You may freely distribute the URL identifying the publication in the public portal.

If the publication is distributed under the terms of Article 25fa of the Dutch Copyright Act, indicated by the "Taverne" license above, please follow below link for the End User Agreement:

www.tue.nl/taverne

Take down policy

If you believe that this document breaches copyright please contact us at:

openaccess@tue.nl

providing details and we will investigate your claim. 


\title{
On the Use of Hand-Held Magnifiers during Reading
}

\author{
JOHAN J. NEVE* \\ Institute for Perception Research, Eindhoven, The Netherlands
}

\begin{abstract}
Little is known about the actual use of magnifiers (or loupes) during reading. In studying the influence of the use of magnifiers on the reading process the reading field is a relevant factor. Four reading fields are distinguished: three horizontal reading fields and the vertical reading field. We examined the influence of a variation in the widths of these fields on the reading behavior of subjects. This was done by measuring two-dimensional loupe movements while subjects read text under conditions that provided a variety of reading field widths. It was found that individual subjects use different reading-field widths depending on loupe dimensions. Most difficulties in reading with a magnifier, especially finding the beginning of a new line, appear to result from the need to move the loupes horizontally in order to read the complete line of text.
\end{abstract}

Key Words: magnifiers, reading fields, low vision, loupe movements, reading rates

The simple hand magnifier (or loupe) is one of the most widely used low-vision aids. These magnifiers can be defined as any positive lens that is used for enlarging the retinal image of an object (especially text) and which is held at any physically realistic distance from the eye.

Hand magnifiers having powers ranging from about +3.0 up to $+20.0 \mathrm{D}$ are often used for reading by the visually impaired. In order to read with such a magnifier, the retinal image of the object has to be large enough and the field of view or readingfield width must include enough characters to make reading possible. However, compared to ordinary reading (without magnification) one might expect magnification of text and limited reading-field width to give rise to difficulties when reading with the aid of a magnifier. ${ }^{1}$

Little is known about the impact of these difficulties on the process of reading with a magnifier. Apart from Blommaert and Neve, ${ }^{2}$ we could not find literature giving more information on how loupes are actually used during reading. Most reports on magnifiers deal with either the classifica-

Received November 29, 1988; revision received March 13, 1989 .

* Physicist, Ph.D., Member of Faculty. tion of these aids or with procedures for prescribing them to the visually impaired, whereas others treat their physical aspects. ${ }^{3-9}$

For understanding the influence of magnifiers on the process of reading, the reading field is a relevant factor. In an earlier paper ${ }^{10}$ we distinguished three different reading fields. These are the monocular reading field, which is the horizontal size of the unmagnified portion of the text that can be seen through a loupe with one eye; the binocular reading field; defined as the overlapping part of two separate monocular fields; and finally the composite reading field, which is a mixture of both. In addition, one should distinguish the vertical reading field, which is the vertical size of the unmagnified portion of the text that can be seen through a loupe.

Whenever the line width and/or the text height is larger than the reading-field width used, the magnifier has to be moved horizontally and/or vertically to read the entire text. Blommaert and Neve ${ }^{2}$ have shown that a better understanding of the use of magnifiers during reading can be obtained by registering loupe movements. By measuring the average total horizontal loupe displacement, they found that subjects may use different strategies when reading through a loupe with both eyes. During reading with both eyes subjects may use one eye, both eyes alternately, or both eyes simultaneously. The method of registering loupe displacements used ${ }^{2}$ was rather general and inaccurate. We succeeded in developing a more accurate method which allows us to determine the position of the loupe at any time during reading. Measurements of loupe position and reading-field widths open the possibility of tracing whether disturbances in the loupe movements occur and provide more insight into the reading strategies actually used.

In this paper we describe two experiments which were carried out in order to learn about the influence of changes in the reading-field widths on reading behavior. This was done by measuring readingfield widths and loupe movements for loupes with different widths and heights. From the experiments more insight is gained into which reading fields are used and how they are used. Results show that horizontal loupe movements make reading with a magnifier more difficult. Reading rates depend on the loupe width as long as the horizontal field width is smaller than the line width. 


\section{THEORETICAL BACKGROUND}

\section{Reading Fields}

A magnifier is used to enlarge the retinal image of an object. The magnified part of the object is limited by the diameter of the magnifying lens. Looking through a loupe with both eyes, two partially overlapping images of the object may be seen: one with the left eye and one with the right eye (see Fig. 1). The information contained in both image fields may, in principle, be used by the observer. First, one may either use only the left or only the right (monocular) reading field. This may be expected when the reader has a dominant eye. Second, both reading fields may be seen binocularly, i.e., they are seen fused and experienced as only one image. A third possibility is that subjects use the information of both monocular fields alternately, i.e., appropriate parts of the text are viewed with one eye, whereas other parts are viewed with the other eye; some parts may be viewed binocularly. In this way the reader makes efficient use of the available information contained in both images.

The widths of these reading fields vary with the focal length (f) and the horizontal width (L) of the loupe as a function of the geometrical parameters eye-to-loupe distance $\left(a_{r}\right)$ and object-to-loupe distance $(v)$. The widths decrease considerably with increasing magnification, as is shown in Blommaert and Neve."

The theoretical expressions for the horizontal field widths are given by:

$$
W_{m}=\left(1+\frac{v}{a_{r}}-\frac{v}{f}\right) L
$$

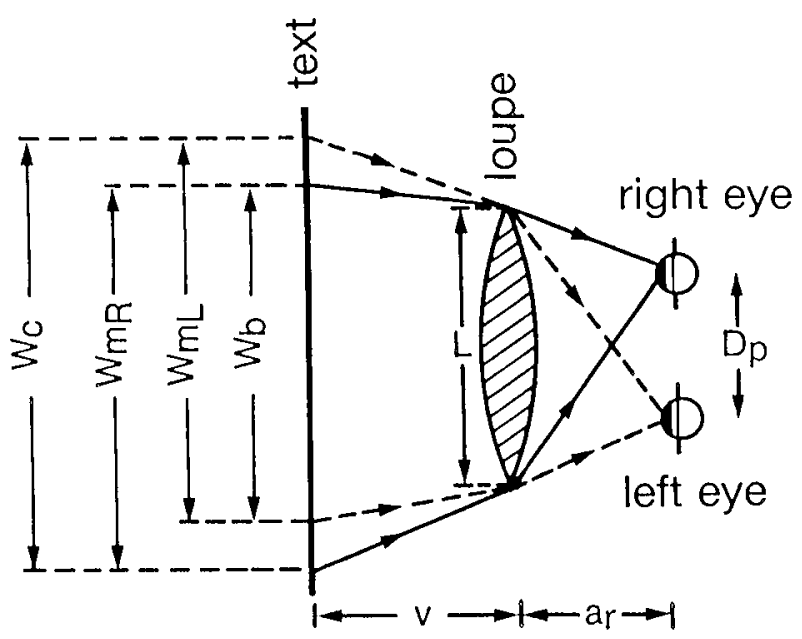

Figure 1. Definitions of the monocular $W_{m}$, binocular $W_{b}$, and composite reading field $W_{c} . W_{m R}$ and $W_{m L}$ indicate the monocular field for the right and the left eye, respectively. The parameters $v, a_{r}, L$, and $D_{p}$ denote the objectto-loupe distance, the eye-to-loupe distance, the loupe width, and the distance between both eye pupils, respectively.

$$
\begin{aligned}
& \mathrm{W}_{\mathrm{b}}=\mathrm{W}_{\mathrm{m}}-\frac{\mathrm{v}}{\mathrm{a}_{\mathrm{r}}} \mathrm{D}_{\mathrm{p}} \\
& \mathrm{W}_{\mathrm{c}}=2 \mathrm{~W}_{\mathrm{m}}-\mathrm{W}_{\mathrm{b}}
\end{aligned}
$$

where $W_{m}$ is the monocular, $W_{b}$ the binocular, and $\mathrm{W}_{\mathrm{c}}$ the composite field width. The interpupillary distance is given by $D_{p}$. The vertical reading field width is given by:

$$
\mathrm{W}_{\mathrm{h}}=\left(1+\frac{\mathrm{v}}{\mathrm{a}_{\mathrm{r}}}-\frac{\mathrm{v}}{\mathrm{f}}\right) \mathrm{H}
$$

where $\mathrm{H}$ corresponds to the height of the magnifier.

In order to interpret data obtained for the experiments described in this paper we need experimental values for the reading-field widths. The values for the monocular reading-field width $\left(W_{m}\right)$, the composite field width $\left(W_{c}\right)$, and the vertical field height $\left(W_{h}\right)$ were measured separately by the following procedure. Subjects look through the loupes with one eye and with both eyes for a fixed eye-toloupe distance and a fixed object-to-loupe distance. The object consists of a white sheet of paper that contains a line of randomized letters that are typed near a line of different numerals and placed horizontally (or vertically for evaluating the vertical width) in the object plane. The subjects are asked to report which combination of letters and numbers they perceive at the extreme right and left loupe edges (see Fig. 2).

When only one eye is used, the experimental results on the horizontal fields are interpreted as being the values for the monocular reading field $W_{m}$. When both eyes are used the results are interpreted as the composite reading field $W_{c}$. Values for the binocular reading-field width $W_{b}$, cannot be determined that directly and so they are derived from the experimental values of $\mathrm{W}_{\mathrm{m}}$ and $\mathrm{W}_{\mathrm{c}}$ according to equation 2. The experimental field widths deviate increasingly from the theoretical ones for larger reading fields. This is in agreement with the findings of Blommaert and Neve. ${ }^{2}$

\section{Loupe Movements}

Reading-field width is defined as the unmagnified portion of the text that can be viewed through a loupe. When the line width and/or text height is larger than such a portion, the loupe has to be moved along the text lines in order to read the complete text. Because the widths of the different reading fields are not the same, a measurement of the widths, together with the determination of the loupe displacements, can give information about which reading field is actually used by a person when reading through a loupe. ${ }^{2}$

We measured the loupe movements with light positioning diode (LPD) equipment. ${ }^{11}$ This measuring system is composed of an optical photodetector device (LPD), an electronic system which measures the electrical signals generated by the LPD and an infrared light emitting diode (LED) 


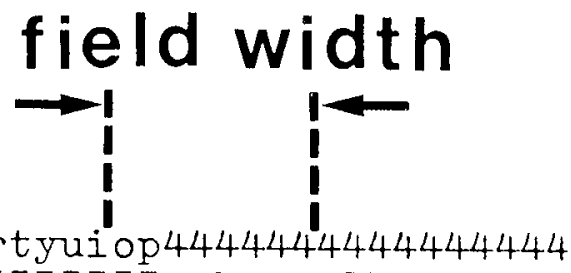

3333333333333 mnbvexzlkjhgfdsa

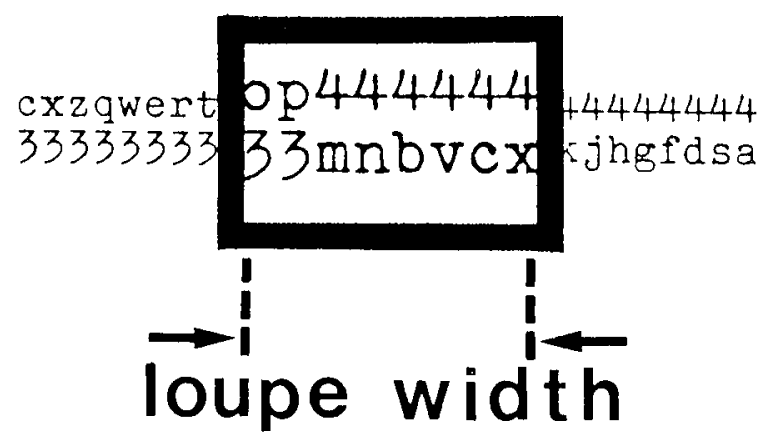

Figure 2. Illustration of the experimental procedure to determine the reading-field width perceived by the subjects. The reading-field width is that part of the unmagnified text which is seen magnified through the loupe.

mounted at the top of the loupe frame. The LED light spot is projected on the sensitive area of the LPD and generates a current in this device. A measurement of the distribution of the current over the electrodes of the two-dimensional LPD gives the position of the light spot on the photodetector from which the position of the LED and therefore the position of the loupe can be calculated.

The horizontal and vertical movements of the center of a loupe during reading are measured simultaneously as a function of time. From these data the two-dimensional movement of the center of the loupe in a plane parallel to the text plane can be calculated. A typical example of a twodimensional loupe movement picture is shown in Fig. 3.

From the two-dimensional loupe movement picture, it is easily seen at which point during reading the loupe movements hamper the most. Information can be obtained on what loupe movement strategies are used.

When subjects read through a loupe with both eyes it is not clear which reading-field width they actually use. They may use one of the monocular fields, the binocular field, or the composite field. In order to decide which horizontal field width is being used, we make use of the positions of the centers of the monocular reading fields in the text plane (see Appendix B) and the measured reading-field widths. The procedure is as follows.

1 . First, we measure the monocular $\left(\mathrm{W}_{\mathrm{m}}\right)$ readingfield widths of the right and left eye from which we calculate the binocular reading-field width $\left(W_{\mathrm{b}}\right)$.

2. Second, we measure the horizontal positions of the center of the loupe at the beginning $\left(\mathrm{x}_{1}\right)$ and at the end $\left(x_{c}\right)$ of the text lines (see Fig. 3).

3 . From these $x_{b}$ and $x_{e}$ values the positions of

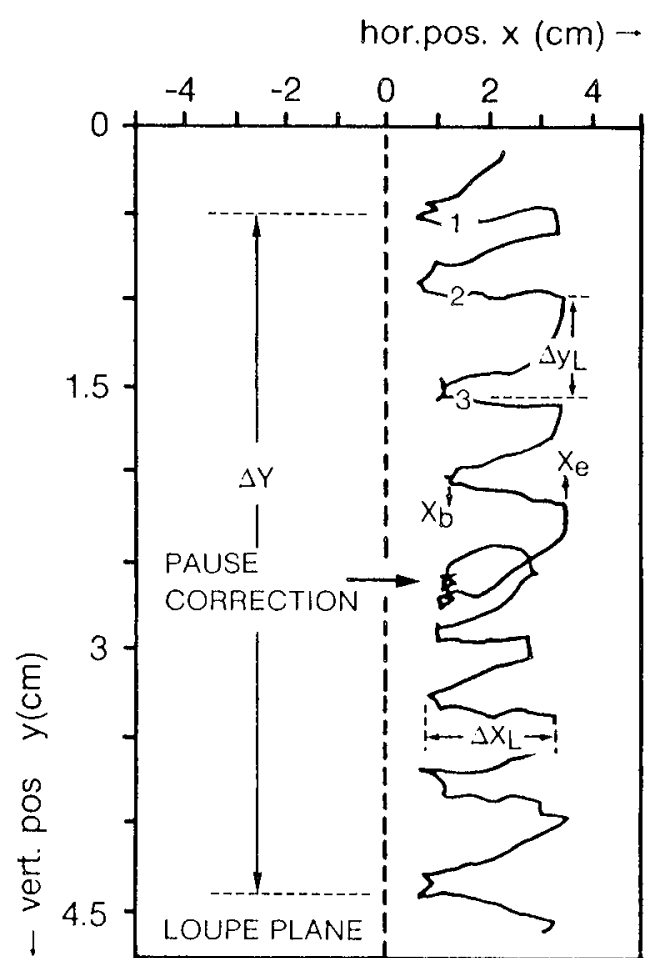

Figure 3. Typical example of a two-dimensional loupe movement track. The following quantities can be determined for each individual line: the time needed to read the line, the time needed to jump to the next line; the position of the center of the loupe at the beginning $\left(x_{b}\right)$ and at the end $\left(x_{e}\right)$ of the line, the total horizontal loupe displacement $\Delta x_{1}$, the number of pauses and corrections in the movements of the loupe, the total vertical loupe displacement $(\Delta Y)$, and the displacement per line $\left(\Delta y_{1}\right)$.

the centers of both monocular reading fields and the binocular field at the beginning $\left[\mathrm{p}_{\mathrm{bR}}, \mathrm{p}_{\mathrm{bL}}\right.$, and $\left.\left(p_{\mathrm{bR}}+\mathrm{p}_{\mathrm{bL}}\right) / 2\right]$ and at the end $\left[\mathrm{p}_{\mathrm{eR}}, \mathrm{p}_{\mathrm{eL}}\right.$, and $\left(\mathrm{p}_{\mathrm{e} R}+\right.$ $\left.\left.p_{\mathrm{cl}}.\right) / 2\right]$ of each line are determined with the equations given in Appendix A.

4. Knowing these positions at the beginning and at the end of a text line, it is apparent which reading field the subject has used. This field width must include the margins at the left and right side of the text. The method is illustrated in Appendix B for a subject reading one line with both eyes uncovered.

When the loupe has to be moved vertically, we can distinguish between the situation in which the loupe also has to be moved horizontally in order to read the entire line and the situation in which the loupe only has to be moved vertically.

In the case where the loupe has to be moved horizontally, one expects that the displacement of the vertical reading field is dictated by the distance between two succeeding text lines (the line spacing). The total displacement of the center of the vertical reading field $(\Delta Q)$ when reading the complete text will then correspond to the height of the text. The vertical displacement per text line $(\Delta q)$ and the total displacement $(\Delta Q)$ of the center of the vertical reading field can be obtained from the measured vertical loupe displacement per line $\Delta \mathrm{y}_{1}$ 
and the total loupe displacement $\Delta Y$ (see Fig. 3) by applying the equations in Appendix A.

Whenever the horizontal field width is larger than the line width and the vertical field width is smaller than the height of the text, the loupe only has to be moved vertically. In this situation different strategies can be used to move the loupe.

Subjects may use only the central part of the vertical reading field. In that case the loupe is moved vertically with each line to be read. Again $\Delta \mathrm{Q}$ will correspond to the height of the text and the track of the vertical loupe movement over time will change step by step, the number of steps corresponding to the number of text lines.

On the other hand subjects may read all the text lines comprised in the vertical field width and then move vertically to read the next series of lines. The value of $\Delta Q$ will then be smaller than the height of the text and the number of steps in the track of the vertical loupe movement over time will decrease with increasing vertical reading-field height and decreasing line spacing.

Finally, subjects may choose a combination of the above mentioned strategies.

\section{METHODS}

Two separate experiments in which loupe movements were measured during reading were performed. In the first experiment the influence of the horizontal reading-field width on the reading performance was studied. In this experiment only horizontal loupe movements were measured, due to technical imperfections of the LPD equipment. Therefore, a second experiment was carried out in which we focused our attention on the influence of the vertical reading-field height. In this experiment both horizontal and vertical movements of the loupes were determined.

Two groups of nine subjects took part in the experiments. Some of the subjects participated in both experiments. In our experiments subjects were asked to read different text fragments silently at an illumination level of 1000 to 1500 lux with the aid of the loupes, with both eyes and with one eye (their dominant eye). The visual acuity of the subjects was reduced to about 0.5 by means of raster foils. These foils simulated loss of acuity and ensured that no interaction could occur between the magnified and unmagnified parts of the text. The text fragments (character size $1.6 \mathrm{~mm} \times$ height) and the different loupes were used in random sequence. For each subject the horizontal readingfield widths $W_{m}$ (one eye uncovered) and $W_{c}$ (both eyes uncovered) and vertical field height $W_{h}$ were measured for each loupe following the method described. From these data the binocular reading-field width was calculated using equation 2 . The eye-toloupe distance $\mathrm{a}_{\mathrm{r}}$ was fixed during reading by means of a forehead rest. Subjects were instructed to move the loupes on a plate of glass which was positioned parallel to the text fragments at a distance of 0.75 $f$, where $f$ is the focal length. The plate of glass formed an angle of about $80^{\circ}$ with the horizontal plane. In this way the loupe-to-text distance $v$ was kept constant during reading. The loupes used had different horizontal field widths and vertical field heights. This was achieved by using loupes with identical focal lengths ( $\mathrm{f}=30.8 \mathrm{~cm}$ ) but with different widths and/or heights.

In both experiments the retinal magnification $\mathrm{M}_{25}$ (that is assuming a reading distance of $25 \mathrm{~cm}$ ) was close to unity, the linear magnification of the text was about $4 \times$, and the distance between the virtual image and the eye was about $110 \mathrm{~cm}$. Movements of the loupes were recorded with the LPD equipment.

In the first experiment for a loupe with a focal length $f$ of $30.8 \mathrm{~cm}$ the theoretical monocular horizontal reading-field width was varied in four steps from 6 to $12 \mathrm{~cm}$. All loupes had the same height $(\mathrm{H}$ $=5.5 \mathrm{~cm}$ ). The eye-to-loupe distance $\mathrm{a}_{\mathrm{r}}$ was taken equal to $\mathrm{f}$, whereas the loupe-to-text distance $\mathrm{v}$ was $0.75 \mathrm{f}$. The theoretical vertical reading-field height $\mathrm{W}_{\mathrm{h}}$ was about $5.5 \mathrm{~cm}$. The theoretical monocular $\left(W_{\mathrm{m}}\right)$, binocular $\left(\mathrm{W}_{\mathrm{b}}\right)$, and composite $\left(\mathrm{W}_{c}\right)$ horizontal field widths varied linearly with the loupe width $\mathrm{L}$ according to equations 1 to 3 . The text fragments had a fixed line width of $18 \mathrm{~cm}$, a line spacing of 6 $\mathrm{mm}$, and a total length of approximately 25 lines. The subjects had to move the loupes horizontally during the reading of a full text line, because all reading-field widths were smaller than the line widths.

In the second experiment for a loupe with a focal length $f$ of $30.8 \mathrm{~cm}$ the vertical reading-field height was varied in three steps $(1.8,3.8$, and $7.7 \mathrm{~cm}$, respectively). All loupes had the same width ( $\mathrm{L}=$ $8 \mathrm{~cm}$ ). The eye-to-loupe distance $a_{\mathrm{r}}$ was taken equal to $20 \mathrm{~cm}$, whereas the loupe-to-text distance $\mathrm{v}$ was $0.75 \mathrm{f}$. The theoretical monocular, binocular, and composite horizontal field widths were 11.2, 4.3, and $18.1 \mathrm{~cm}$, respectively. The text fragments had a line width of either 12 or $6 \mathrm{~cm}$ with line spacing of 6,9 , or $12 \mathrm{~mm}$. The height of the text fragments was about $10 \mathrm{~cm}$. The number of lines in the text fragments varied with the line spacing used. The subjects had to move the loupes vertically while reading the full text because all vertical readingfield heights were smaller than the text lengths. Whether subjects moved the loupes horizontally depended on the horizontal reading-field width they actually used during reading.

The first experiment examined the influence of the horizontal reading-field width on the reading performance of nine subjects. Experimental values for the monocular and composite field width were measured. In this experiment the loupes had to be moved horizontally inasmuch as all horizontal reading-field widths were smaller than the line width. Only horizontal loupe movements were determined. In the second experiment the influence of the vertical reading-field height on the reading performance was studied. Experimental values for the monocular, composite horizontal field widths, and ver- 
tical field height, as well as horizontal and vertical loupe movements, were measured.

\section{RESULTS}

The following experimental results were obtained.

1. The overall course of the loupe movements is illustrated in Fig. 3. It can be seen that the loupe is moved smoothly rather than discontinuously, especially in the horizontal direction. This was true for all subjects regardless of the loupe width.

2 . The velocity with which the loupe is moved forward to read a line and the velocity with which the loupe is moved backward to the beginning of the next line are not affected by the loupe width. The velocity with which the loupe is moved to the next line is about 3 times greater than the velocity with which the loupe is moved forward. Subjects with the lowest reading rate move the loupe to the next line nearly as rapidly as the subjects with the highest reading rate.

3. From plots such as those given in Fig. 3, we found that pauses and corrections in horizontal loupe movement are attended by pauses and corrections in vertical movement. The average number of pauses and corrections per line in the two-dimensional movement made by subjects in the second experiment during reading with loupes with $\mathrm{H}$ $=1.3,2.7$, and $5.5 \mathrm{~cm}$ is shown in Fig. 4 .

The pauses and corrections were counted at the immediate beginning of the line, in the line itself, and at the immediate end of the line. In the figure no distinction is made between the data obtained for text fragments with different line spacing. It is

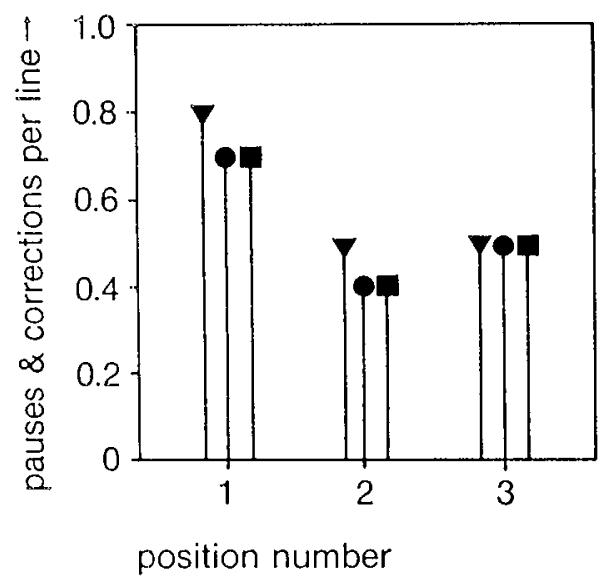

Figure 4. Average number of pauses and corrections in the loupe movements per line for three loupe heights $(\boldsymbol{\nabla}$, $\mathrm{H}=1.3 \mathrm{~cm} ; \boldsymbol{O}, \mathrm{H}=2.7 \mathrm{~cm}$; and $\mathbf{D}, \mathrm{H}=5.5 \mathrm{~cm}$ ) and three positions; 1 corresponds to the beginning of the text line. 2 corresponds to the position in the text line itself, and 3 corresponds to the end of the text line. It should be stressed that the areas in which pauses and corrections were counted do not have the same dimensions for the different position numbers. The areas corresponding to positions 1 and 3 were much smaller than the one corresponding to position 2 . The data were obtained for reading text fragments with a line width of $12 \mathrm{~cm}$ monocularly. apparent from this figure that pauses and corrections tend to occur more frequently at the beginning of a line than at the end, or in the line itself. The pauses and corrections were counted for reading monocularly (one eye covered) text fragments with a line width of $12 \mathrm{~cm}$. In this case the loupes have to be moved horizontally. Similar results occurred when reading with both eyes as long as the subjects moved the loupes horizontally. The mean number of pauses per line and their duration is not influenced by the loupe width $\mathrm{L}$ regardless of whether one eye or two eyes were used to look through the loupe. When the loupes were not moved horizontally (particularly for line widths of $6 \mathrm{~cm}$ in the second experiment), pauses and corrections in the two-dimensional loupe movement occurred only occasionally.

4. In Fig. 5 the average reading rate (words $/ \mathrm{min}$ ) for nine subjects in the first experiment is given as a function of the loupe width. The solid symbols correspond to the monocular situation (one eye covered); the open symbols to the situation where both eyes are uncovered. The reading rate increases with increasing field width. The highest reading rates are obtained for reading with both eyes through the loupes with the largest widths. These tendencies were found for all subjects. The spread on the reading rates' values is about 25 words $/ \mathrm{min}$.

No significant effect of broader loupe width on the reading rate occurred as long as the horizontal field widths covered the entire line width. There was a tendency toward higher reading rates for larger loupe heights when the loupes did not have to be moved horizontally.

5 . When subjects are reading through a loupe with one eye, they are using the monocular field. When reading through a loupe with both eyes, we

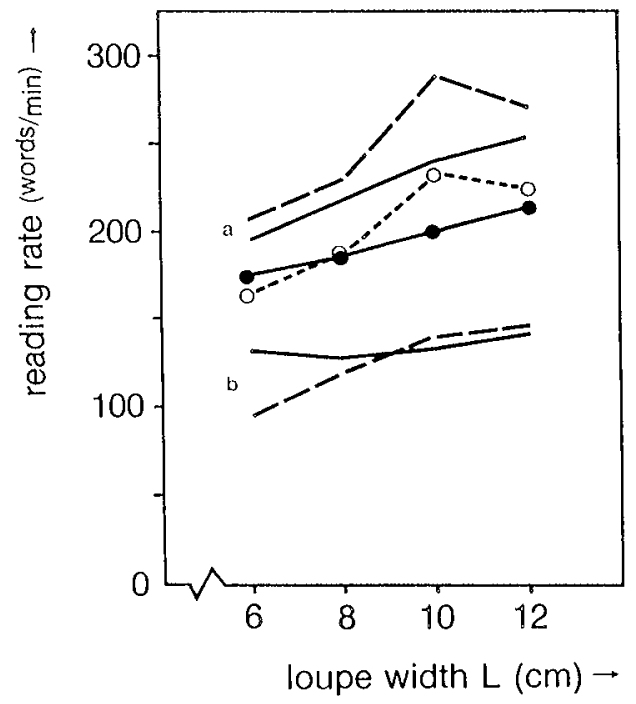

Figure 5. Reading rate vs. loupe width $L$. The solid $(\bullet)$ and open $(O)$ symbols represent the reading rate values averaged over the nine subjects when reading with one eye and both eyes, respectively. The curves denoted with (a) give these values for the six "fast" readers. The curves denoted with (b) represent the three "slow" readers. 
do not know whether only one eye (left or right), both eyes simultaneously, or both eyes alternately are being used. In other words, we do not know whether the subjects use the monocular, the binocular, or the composite reading field. Using the LPD equipment we are able to register loupe movement accurately and to specify for each individual line which reading-field subjects actually use by applying the procedure described in Appendix B.

The following tendencies were found for all subjects and all loupe widths. Subjects may change their strategy while reading a text fragment with a particular loupe. Some lines are read monocularly; other lines may be read binocularly or by making alternate use of the eyes. For all loupe widths most subjects read monocularly or used the composite reading field, i.e., text parts at the left margin were viewed with the right eye, whereas text parts at the right margin were viewed with the left eye. Subjects tend to use the composite field more for increasing loupe widths; however, some subjects use the composite field even for loupe widths as low as $L=6$ $\mathrm{cm}$.

6. These findings were confirmed in the second experiment in which horizontal as well as vertical loupe movements were measured. Subjects tended to use the monocular field for smaller loupe heights.

Because all text fragments had a height of $10 \mathrm{~cm}$, the subjects had to move the loupes vertically to read the entire text.

When the loupes are moved horizontally, the vertical displacement of the loupe is dictated by the line spacing. The vertical displacement per line $(\Delta q)$ of the center of the vertical reading field equals the line spacing for all loupe heights and all line spacings.

When the loupes are not moved horizontally, subjects may use different strategies when displacing the loupes vertically. This is illustrated in Fig. 6.

In this figure the points represent the measured total vertical field displacement $\Delta Q$ and the straight line gives the least theoretical field displacement necessary to read a text completely with a length of $10 \mathrm{~cm}$.

In Fig. 6 measured values for $\Delta Q$ and the vertical reading-field height $W_{h}$ are given for subjects $E H$ and $W W$ reading text fragments with a line width of 6 and $12 \mathrm{~cm}$, respectively.

For subject $\mathrm{EH}$ the values of $\Delta \mathrm{Q}(\boldsymbol{\Delta})$ obtained for different line spacings while looking through the loupe with one eye and both eyes are averaged. The spread on these $\Delta Q$ values is about $0.2 \mathrm{~cm}$. It can be seen from Fig. 6 that subject $\mathrm{EH}$ displaces the center of the vertical reading field over a distance which nearly equals the text height $(10 \mathrm{~cm})$. This strongly indicates that EH uses only the central part of the vertical reading field, independently of the vertical field height, the line spacing, and whether one eye or two eyes are used.

The circles in Fig. 6 represent the $\Delta Q$ values for subject WW reading text fragments with a line

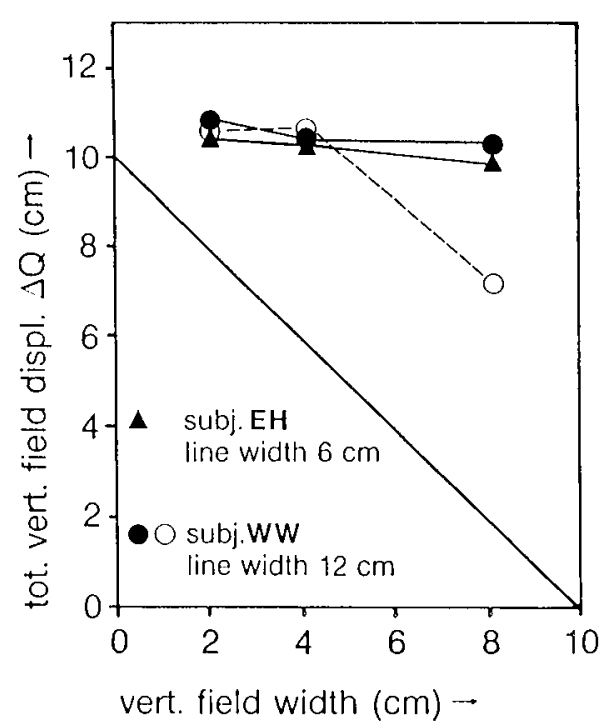

Figure 6. Total vertical reading field displacement $\Delta Q$ for subjects EH and WW as a function of the experimental vertical reading field height. The text fragments had a line width of $6 \mathrm{~cm}$ for $\mathrm{EH}$ and $12 \mathrm{~cm}$ for WW, respectively. The triangles $(\mathbf{\Delta})$ represent the average values of $\Delta \mathrm{Q}$ for subject $\mathrm{EH}$ obtained for different line spacings while looking through the loupes $(f=30.8 \mathrm{~cm}, L=10 \mathrm{~cm}$, and $H=1.3$, 2.7 , and $5.5 \mathrm{~cm}$, respectively) with one eye and both eyes. The spread on these values is about $0.2 \mathrm{~cm}$. The open symbols $(O)$ represent the data obtained for WW for reading through the loupes with both eyes uncovered. The full symbols $(\bullet)$ correspond to reading through these loupes with one eye.

width of $12 \mathrm{~cm}$ and a line spacing of $12 \mathrm{~mm}$. Note the difference between the curves for reading with one eye (O) and both eyes $(O)$. When reading with one eye the horizontal reading field width $\left(\mathrm{W}_{\mathrm{m}}\right)$ is smaller than the line width $(12 \mathrm{~cm})$ and the loupe has to be moved horizontally. Therefore the vertical displacement of the loupe is dictated by the line spacing and $\Delta \mathrm{Q}$ corresponds to the total text length $(10 \mathrm{~cm})$ for all values of $W_{\mathrm{h}}$. When looking through the loupe with both eyes, WW did not move the loupe horizontally because the composiite field was being used. Therefore the subject could choose between different strategies to move the loupe vertically. Fig. 6 shows that the subject uses only the center part of the vertical field for the smaller loupe heights; for the largest loupe height the subject makes use of the increased vertical height.

Although subjects may use different strategies when using the vertical reading field depending on loupe height and line spacing, our measurements of $\Delta Q$ for all subjects show that in most cases the subjects use only the center part of the vertical reading field height. That is, the subjects move the loupe vertically with every line they read.

\section{DISCUSSION}

Some of the difficulties that might occur when reading through a loupe have been suggested by Bouma et al. ${ }^{1}$ and Blommaert and Neve." They 
expect the limitation of the reading field will disturb the normal reading process. This disturbance should occur mainly when the magnified text part is smaller than the line width. In that case it is necessary to shift the loupe horizontally to read a full line and loupe movements have to be tuned to eye movements. The loupe movements will cause visible movements of the enlarged text relative to the unmagnified text, in a direction opposite to the direction of the loupe movements. This disturbs the reading process, especially if the beginning of a new line has to be found. Finding a new line becomes even more difficult because parallax disturbs the orientation of the reader's eye concerning the location of the left margin. These orientation problems are expected to impede the integration of eye movements with loupe movements, to slow down the reading process, or even to interrupt it.

The experimental results presented confirm this point of view and provide insight into the actual use of the horizontal field widths and vertical field height during reading.

A global analysis of the measured loupe movements shows that the loupes are moved forward and backward without leaps. This might indicate that the loupe movements are coordinated with eye movements fairly smoothly. Pauses and corrections in loupe movements occur more frequently at the beginning of a new line, whenever the loupes have to be moved horizontally in order to read the full line. Pauses and corrections in horizontal loupe movement at the beginning of a new line are frequently accompanied by a correctional movement of the loupe in the vertical direction. This indicates that at this point coordination of loupe movements and eye movements is most hampered, causing difficulties in finding the beginning of a new line. When the loupes do not need to be moved horizontally, correctional movements of the loupe occurred only occasionally, indicating that finding a new line is less troublesome in this situation.

The actual handling of the loupes does not cause serious difficulties inasmuch as the subjects with the lowest reading rate moved the loupes to the next line nearly as rapidly as the subjects with the highest reading rate. However, note that in the experiments the loupes were moved along an almost vertically positioned plate of glass. This might have minimized the difficulties in handling the loupes.

The velocity with which the loupe is moved forward is found to be independent of the loupe width. This does not mean that the reading rates are independent of the loupe width. Loupes with a large width do not have to be displaced as much as smaller loupes. Reading rates increased with increasing field width as long as the loupes had to be moved horizontally. The highest reading rates were found for reading with both eyes through the loupes with the largest widths $(L=10$ and $12 \mathrm{~cm})$. When the horizontal field widths covered the entire line width, no significant effect of an increasing loupe width on the reading rate was found. There was a tendency toward higher reading rates for the largest loupe height when the loupes did not have to be moved horizontally.

These tendencies were found for nearly every subject, which again indicates that limitation of the reading field does influence the reading process. The reading rates are similar to those found for reading at a distance of about $30 \mathrm{~cm}$ for subjects with normal and low visual acuity. ${ }^{12,13}$

When subjects look through the loupe with both eyes, it is not apparent whether they use one eye or both eyes for reading. Bouma et al. ${ }^{1}$ implicitly assumed that subjects used the binocular field width. In the present paper it is shown that by measuring the monocular field width and the extreme positions of the center of the loupe, one can deduce for each individual text line which strategy has most likely been used. The choice of a particular reading field width may differ from loupe width to loupe width. However, there was a tendency to use the monocular field for small loupe widths and to use the composite field for larger loupe widths. The fact that subjects have the option of choosing between different strategies when reading through a loupe has been noticed earlier. ${ }^{2}$ Blommaert and Neve reached this conclusion from measurements of the average horizontal loupe displacement. The present results are more convincing because they are based on precise measurements and give information for each text line.

When the composite field is used, the retinal images of both eyes will be used alternately and the overlapping part of the images might be fused. It cannot be deduced from our experimental results whether this fusion occurs. It is unclear where in the text line the subjects shift from reading with the right eye to reading with the left eye.

The results on the total vertical loupe displacement show that whenever the loupes have to be moved horizontally, the vertical displacement is dictated by the line spacing. All subjects preferred the situation in which the loupe did not have to be moved horizontally. For horizontal reading-field widths larger than the line widths the subjects may choose different strategies to move the loupes vertically; they may, for instance, read the number of lines comprised in the vertical reading field and then move to the next series of lines to read. However, most of the time subjects use only the central part of the vertical reading field. They move the loupe vertically with every line read, more or less independently of the loupe height. Although we did not identify an optimal loupe height for reading, the largest loupe height $(\mathrm{H}=5.5 \mathrm{~cm})$ is preferable to the smallest loupe height $(\mathrm{H}=1.3 \mathrm{~cm})$ because somewhat higher reading rates were obtained with $\mathrm{H}=5.5 \mathrm{~cm}$ when reading with both eyes and the limited vertical field height for $\mathrm{H}=1.3 \mathrm{~cm}$ makes the accuracy with which the loupe has to be moved vertically more critical.

In our experiments a retinal magnification (based on a reading distance of $25 \mathrm{~cm}$ ) of about unity was 
obtained by using low-powered magnifiers in a geometrical configuration given by eye-to-loupe and loupe-to-text distances of about $20 \mathrm{~cm}$ and $0.75 \mathrm{f}$, respectively. These distances were chosen because they come close to the distances that the partially sighted prefer when reading in a comfortable posture with a hand-held magnifier. Our experiments were designed to study the influence of the readingfield widths on the reading process. Therefore, lowpowered magnifiers were chosen because these have a relatively large width and produce virtual images which are almost free of aberration.

The subjects that participated in our experiments were normally sighted. Their visual acuity was reduced to about 0.5 by means of raster foils. One may wonder to what extent our experiments simulate the difficulties encountered by the visually impaired when reading with a magnifier. In our experiments the subjects used different strategies while reading through a loupe with both eyes. With regard to the horizontal reading-field width, they tended to use the monocular reading field for smaller loupe widths and the composite field for larger loupe widths. Their reading rates increased with increasing field width, as long as the loupes had to be moved horizontally.

In preliminary experiments comparable results have been found for visually impaired subjects (near visual acuity from 0.1 up to 0.5 ) using hand-held magnifiers with powers up to $10 \mathrm{D}$. The visually impaired often use the monocular field of their best eye when reading through a loupe with both eyes. Some of them were found to use the composite field, whereas none used the binocular field width. Visually impaired persons often need higher retinal magnification than used in the experiments described in this paper. ${ }^{12,14} \mathrm{~A}$ higher magnification produces a further limitation of the reading field width. A limited field width disturbs the reading process, especially when the loupe has to be moved horizontally to read the full text. The location of the beginning of a new line will become even more troublesome using high-powered magnifiers, because the parallax effect and the visible movement of the magnified text relative to the unmagnified text will be enhanced.

As has been shown in this paper, difficulties in reading with a magnifier occur especially when the loupe has to be moved horizontally. This finding suggests the use of loupes with widths as large as possible. However, increasing the width of a magnifier does not provide a straightforward solution to these difficulties. Severe lens aberrations are introduced by increasing the width of high-powered loupes. These aberrations occur at the edges of the loupes and may force the reader to use only the center part of the loupe, which is more or less aberration-free. Therefore, aberrations can reduce the benefits of a larger loupe width. In addition, the retinal images of both eyes are different. In order to fuse them, a certain amount of coherence between the separate images is necessary. Whenever the two images seen through a loupe overlap only slightly or differ markedly as a result of aberration, fusion of both images will be difficult, and hence the monocular field of one eye (the dominant eye) will be used, otherwise the rivalry between the two eyes seriously reduces the comfort of reading with the magnifier. ${ }^{15}$

As has been shown, the width of the reading field is an important quantity in reading with a magnifier. However, the reading performance of partially sighted persons does not depend only on this width. Their performance also depends on the amount of retinal magnification required, the weight of the magnifier, the illumination of the text, their reading posture, and the nature of their ocular problem. In addition concentration, motivation, and reading experience are factors which play an important role in using reading aids. ${ }^{16.18}$ Therefore the impact on the reading performance of the properties of hand magnifiers, such as magnification factor, field width, aberrations, and weight, as well as the impact of certain individual factors should be considered carefully when prescribing hand-held magnifiers for a partially sighted person.

\section{CONCLUSION}

Registration of loupe movements by means of LPD equipment gives valuable information on the usage of loupes during reading. Different readingfield widths are used when reading through a loupe with both eyes. For smaller loupe widths subjects use the monocular field of their dominant eye. For increasing loupe widths they tend to use the composite field; that is, they use the monocular field width of their right eye at the beginning of a line and the monocular field width of the left eye at the end a line. They use mainly the center part of the vertical field height. Horizontal loupe movements impede the reading process, especially at the beginning of a line. A situation in which the loupes do not need to be moved horizontally is preferred. The highest reading rates are reached when reading through the loupes with both eyes. The rates increase with increasing loupe width as long as the loupes have to be moved horizontally. Similar results have been found for the visually impaired using hand magnifiers with smaller focal lengths. Our results suggest that magnifiers with the largest possible widths should be used for reading. However, aberrations limit the effective widths of the reading fields.

The reading performance of the partially sighted using hand-held magnifiers for reading will depend on the properties of the magnifier as well as on individual factors. The impact of these quantities should be assessed carefully when prescribing a specific magnifier.

\section{APPENDIX A}

Provided that the position of the eyes is wellknown, the horizontal (p) and vertical (q) positions 
of the centers of the monocular reading fields of both eyes in the text plane can be calculated from the positions $(x, y)$ of the center of the loupe. This can be seen in Fig. 7.

From similar triangles one obtains

$$
\begin{aligned}
& p_{\mathrm{l}}=\frac{\mathrm{a}_{\mathrm{r}}+\mathrm{v}}{\mathrm{a}_{\mathrm{r}}} \mathrm{x}-\frac{\mathrm{v}}{2 \mathrm{a}_{\mathrm{r}}} \mathrm{D}_{\mathrm{p}} \\
& \mathrm{p}_{\mathrm{I}}=\frac{\mathrm{a}_{\mathrm{r}}+\mathrm{v}}{\mathrm{a}_{\mathrm{r}}} \mathrm{x}+\frac{\mathrm{v}}{2 \mathrm{a}_{\mathrm{r}}} \mathrm{D}_{\mathrm{p}}
\end{aligned}
$$

where the text-to-loupe distance is given by $\mathrm{v}$ and $a_{r}$ represents the distance between the loupe and the center of rotation $C$ of the eye. $D_{p}$ denotes the distance between both eye pupils, whereas $\mathrm{p}_{\mathrm{I}}$, and $\mathrm{p}_{\mathrm{I}}$ correspond to the horizontal positions of the center of the monocular reading fields of the left and right eye, respectively. It should be noted that the coordinates $x$ and $p$ have negative values when they are situated to the left of the dashed line of symmetry. The vertical positions of the centers of both monocular reading fields are given by $\mathrm{q}_{R}$ and $\mathrm{q}_{\mathrm{L}}$, respectively. Assuming that the vertical fields of the right and left eye coincide, the expression for $\mathrm{q}_{\mathrm{R}}$ and $\mathrm{q}_{\mathrm{L}}$, can be obtained from equations 5 and 6 by substituting $D_{p}=0$ and replacing $\mathrm{x}$ by $\mathrm{y}$ :

$$
\mathrm{q}=\mathrm{q}_{\mathrm{R}}=\mathrm{q}_{\mathrm{L}}=\frac{\mathrm{a}_{\mathrm{r}}+\mathrm{vy}}{\mathrm{a}_{\mathrm{r}}}
$$

The positions of the centers of the binocular read-

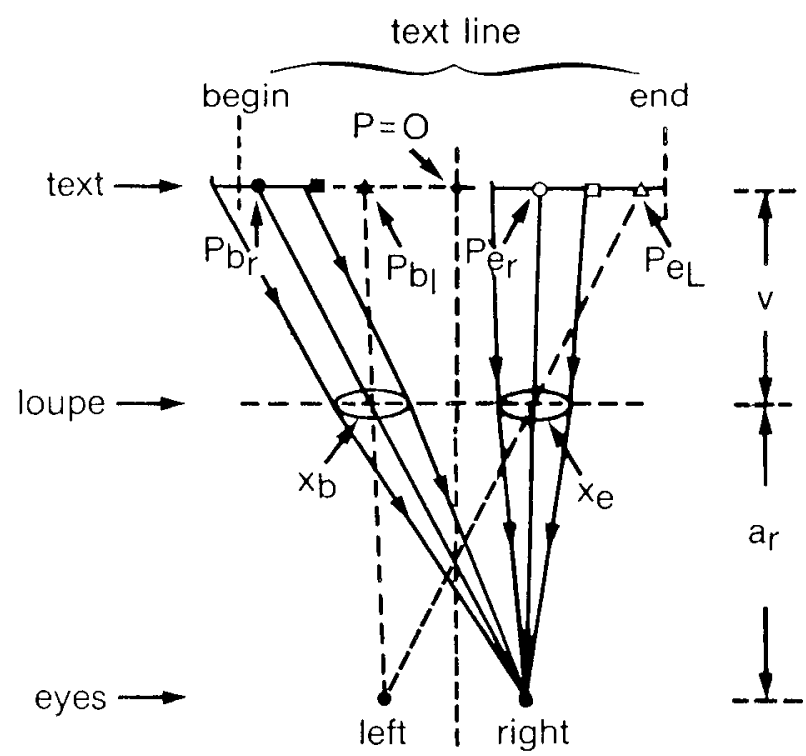

Figure 7. Definitions of the centers of the monocular reading fields at the beginning and the end of a text line. The quantities $p_{D R}(\Theta)$ and $p_{e R}(O)$ correspond to these positions for the right eye; $p_{\mathrm{bL}}(\mathbf{\Lambda})$ and $\mathrm{p}_{\mathrm{eL}}(\triangle)$ correspond to these positions for the left eye. The centers of the binocular reading field at the beginning $(\square)$ and end $(\square)$ of $a$ text line are situated at $\left(p_{b L}+p_{b R}\right) / 2$ and $\left(p_{e L}+p_{e R}\right) / 2$ respectively. The quantities $x_{b}$ and $x_{e}$ indicate the positions of the center of the loupe at the beginning and at the end of the line, respectively.

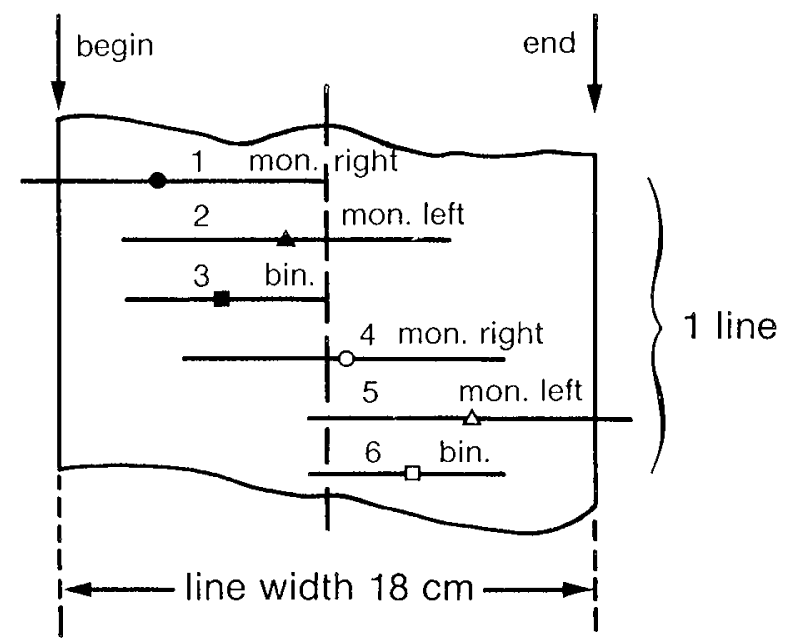

Figure 8. One line read by subject TK with both eyes uncovered. The loupe has a width of $12 \mathrm{~cm}$. The solid symbols give the positions of the centers of the monocular fields ( $(\mathbf{0}$, right eye; $\mathbf{\Lambda}$, left eye) and the binocular field $(\boldsymbol{\square})$ at the beginning of the text line. The open symbols represent these positions at the end of the text line. The horizontal bars indicate the measured monocular and binocular field widths.

ing field and composite reading fields are situated at $\left[\left(\frac{p_{12}}{2}+\frac{p_{\mathrm{L}}}{2}\right), q\right]$.

\section{APPENDIX B}

The method which is used to decide which reading-field width is used when reading through a loupe with both eyes is illustrated in Figs. 7 and 8 for a subject reading one line with both eyes uncovered.

Fig. 7 shows the positions of the center of the loupe at the beginning $\left(\mathrm{x}_{\mathrm{b}}\right)$ and at the end of the line $\left(\mathrm{x}_{\mathrm{e}}\right)$. From $\mathrm{x}_{\mathrm{b}}$ and $\mathrm{x}_{\mathrm{e}}$ the positions of the centers of the monocular fields of both eyes and the positions of the binocular field at the beginning and at the end of a line are calculated. The corresponding reading-field widths are given by the horizontal bars in Fig. 8.

It can be seen from Figs. 7 and 8 that the subject has used the monocular reading field of the right eye at the beginning of the line and the monocular reading field of the left eye at the end of the line, inasmuch as these reading fields are the only ones which include the margins at the left and right side of the text line. In other words, the subject has changed from his right eye to his left eye while reading the line.

\section{ACKNOWLEDGMENTS}

I thank H. E. M. Mélotte for his stimulating interest, F. J. J. Blommaert for helpful criticism, and L. Oosterhof, A. M. F. Heuveimans, and J. J. B. Stakenborg for their technical assistance. This research was supported by the Dutch Innovation Research Programme on Aids for the Handicapped (IOP-HG). 


\section{REFERENCES}

1. Bouma $H$, Mélotte HEM, Blommaert FJJ. On the field width of reading magnifiers. IPO Annual Progress Report 1984;19:133-6.

2. Blommaert FJJ, Neve JJ. Reading fields of magnifying loupes. J Opt Soc Am A 1987;4:1820-30

3. Linksz A. Optical principles of loupe magnification. Am J Ophthalmol 1955:40:831-40

4. Westheimer $\mathrm{G}$. The field of view of visual aids. Am J Optom Physiol Opt 1957;34:430-8.

5. Sloan LL. Reading Aids for the Partially Sighted: A Systematic Classification and Procedure for Prescribing. Baltimore: Williams \& Wilkins, 1977.

6. Bailey IL. Combining hand magnifiers with spectacle additions. Optom Mon 1980;71:458-61.

7. Fonda GE. Management of Low Vision. New York: ThiemeStratton, 1981

8. Jackson J, Silver J. Visual disability. Pt 2: hand magnifiers. Ophthal Opt 1983;23:29-35

9. Brilliant R. Magnification in low vision aids made simple. J Vis Impairment Blind 1983;77:169-71.

10. Blommaert FJJ, Neve JJ, Mélotte HEM. Reading magnifiers: variation in magnification, image distance and field width. IPO Annual Progress Report 1985;20:123-30

11. Neve JJ. Experimentally determined loupe movements. IPO Annual Progress Report 1986;21:99-109.
12. Bouma H, Legein ChP, Mélotte HEM, Zabel L. Is large print easy to read? Oral reading rate and word recognition of elderly subjects. IPO Annual Progress Report 1982;17:8490.

13. Krischer CC, Meissen RM. Reading under real and simulated visual impairment. J Vis Impairment Blind 1983;77:386-8.

14. Legge GE, Rubin GS, Pelli DG, Schleske MM. Psychophysics of reading-II. Low vision. Vision Res 1985;25:253-65.

15. Duwaer AL, van den Brink $G$. What is the diplopia threshold? Percept Psychophys 1981;29:295-309.

16. Goodrich GL, Mehr EB, Darling NC. Parameters in the use of CCTV's and optical aids. Am J Optom Physiol Op 1980;57:881-92.

17. Legein ChP, Bouma H. Reading and the ophthalmologist Doc Ophthalmol 1982;53:123-57.

18. Krischer CC, Stein-Arsic M, Meissen R, Zihl J. Visual performance and reading capacity of partially sighted persons in a rehabilitation center. Am J Optom Physiol Opt 1985;62 $52-8$.

AUTHOR'S ADDRESS

Johan J. Neve

Institute for Perception Research

P.O. Box 513

$5600 \mathrm{MB}$ Eindhoven

The Netherlands

\section{NOTICE}

Continuing Education Program. International Cornea and External Ocular Disease Update-December 1 and 2, 1989

Four Seasons Hotel, Toronto. AMA Category I study credits.

Contact: Continuing Education

Faculty of Medicine,

University of Toronto,

Medical Sciences Building,

Toronto, Ontario Canada M5S 1 A9

(416) $978-2718$ 